This item was submitted to Loughborough's Research Repository by the author.

Items in Figshare are protected by copyright, with all rights reserved, unless otherwise indicated.

\title{
A shorter cricket pitch improves decision-making by junior batters
}

\section{PLEASE CITE THE PUBLISHED VERSION}

https://doi.org/10.1080/02640414.2019.1606760

\section{PUBLISHER}

(c) Taylor and Francis

\section{VERSION}

AM (Accepted Manuscript)

\section{PUBLISHER STATEMENT}

This is an Accepted Manuscript of an article published by Taylor \& Francis in Journal of Sports Sciences on 19 April 2019, available online: http://www.tandfonline.com/10.1080/02640414.2019.1606760.

\section{LICENCE}

CC BY-NC-ND 4.0

\section{REPOSITORY RECORD}

Harwood, Mike, Fred Yeadon, and Mark King. 2019. "A Shorter Cricket Pitch Improves Decision-making by Junior Batters”. figshare. https://hdl.handle.net/2134/37637. 


\title{
A shorter cricket pitch improves decision-making by junior batters
}

\author{
${ }^{1}$ Michael J. Harwood, Maurice R. Yeadon and Mark A King \\ ${ }^{1}$ School of Sport, Exercise and Health Sciences, Loughborough University, Leicestershire, LE11 3TU, UK
}

\begin{abstract}
This study sought to determine whether playing on a shorter cricket pitch would lead batters to make more appropriate decisions about whether to play front foot or back foot shots. Based on an analysis of the shots played by top order batters against seam bowling in county under-10 matches, an age-specific "good length" region between 5.0 yards and 6.5 yards $(4.57$ to $5.94 \mathrm{~m})$ from the batters' stumps was derived. This was where batters were uncertain whether to play on the front or back foot. It was then possible to define deliveries as "short" or "full" depending upon whether they bounced further from or nearer to the batter than the good length region. Club under-11 and county under-10 match data revealed that when playing on a 16 yard pitch batters played more back foot shots to short balls and county batters also played more front foot shots to full balls compared with matches on the currently recommended 20 or 19 yard pitches. For batters a shorter pitch should strengthen the coupling between perception of delivery length and appropriate shot selection, and the increased task demand should lead to improved anticipation, both key features of skilled batting.
\end{abstract}

Keywords: pitch length; perception-action coupling; anticipation; modified sport; good length

\section{INTRODUCTION}

In cricket, batters have an array of shots from which to choose in order to combat the variety of pace, seam, bounce, swing and spin with which the bowlers may try to defeat them. The most basic decision of whether to play forwards or backwards is based on where the ball bounces and learning to "pick the length" is fundamental to successful batting. Woolmer, Noakes, \& Moffett (2008) said "being able to move forward and back correctly greatly increases the chances of success; therefore early and accurate judging of length becomes vital" (p. 96).

The decision about whether to play forward, that is move the foot nearest the bowler towards the ball, or play back, moving the other foot back towards the batter's stumps, depends on how far from the batter the ball is going to bounce (Bradman, 1958; Woolmer et al., 2008). If a delivery is going to bounce close enough to the batter, that is a "full ball", he or she will step towards the ball and attempt to strike it before or soon after it bounces, making what is known as a front foot shot. A ball landing further from the batter, a "short ball", will usually be played with a back foot shot.

Clearly the ball sometimes bounces at distances where the batter could reasonably play forward or back, or possibly is unsure which is the correct choice (Pinder, Davids, \& Renshaw, 2012). These deliveries were defined by Sir Donald Bradman as good length balls, "The type of delivery which has the striker in two minds as to whether he should play forward or back" (Bradman, 1958, p.97). This definition has been paraphrased many times and several have also specified a distance or range of distances from the batters' end stumps for this bounce point in order to create this indecision for adult batters (Figure 1). 


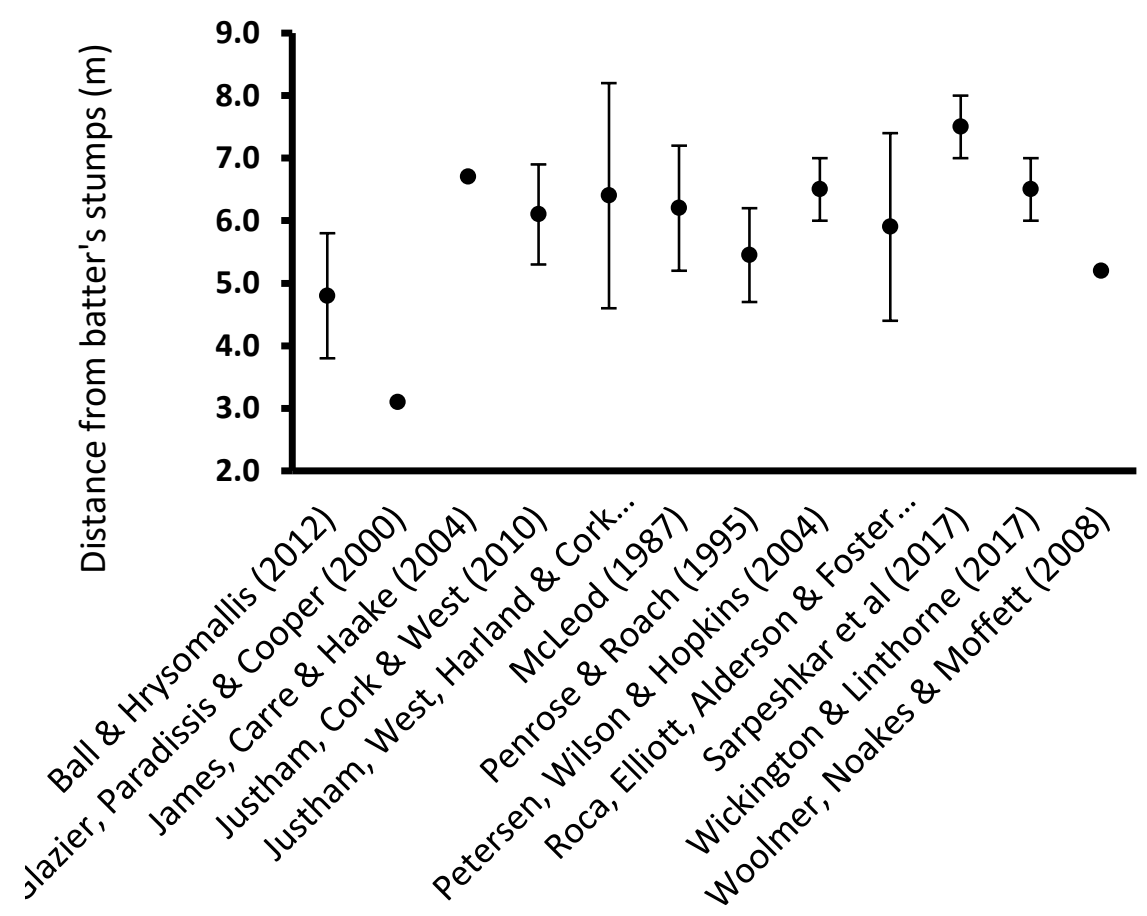

Figure 1. Good length estimates for adults (centre of region and range where specified).

Good length regions for adults appear to centre on a distance approximately 6 $\mathrm{m}$ from the batters' stumps (the median value from the studies in Figure 1 is $6.15 \mathrm{~m}$ ). This corresponds with the distance at which Abernethy \& Russell (1984) found a marked drop in response accuracy, compared with balls bouncing shorter or fuller, by batters of all skill levels. However, Woolmer et al. (2008) pointed out that the reach of the batter, pace and bounce of the pitch and match situation can all influence what is considered to be a good length, as do the trajectory differences between pace or seam and spin bowling. In fact, McLeod (1987) proposed that a good length wasn't a fixed distance but is "just less than 200 ms away from the batsman" (p. 59), which may be true but is unlikely to be useful advice from coach to bowler. The literature provides little guidance on where the good length region lies for junior age groups, although Pinder, Davids, \& Renshaw (2012) used a scaling method based on batters' stature to calculate target regions for bowlers.

According to McLeod (1987) whether to play forward or back to a delivery is the first decision a batter must make. In junior cricket in particular, where deviation of the ball in flight or off the ground is less pronounced, judging the length is the fundamental decision for the batter. Skilled batters are thought to make this judgement on the basis of the early flight of the ball, cues picked up from the bowler's pre-delivery movements, and potentially using situational probability (Abernethy \& Russell, 1984; Brenton, Müller, \& Mansingh, 2016; Müller et al., 2009; Müller, Abernethy, \& Farrow, 2006; Müller \& Abernethy, 2006; Weissensteiner, Abernethy, Farrow, \& Müller, 2008). However, in under-11 club matches on current pitch lengths nearly one fifth of deliveries initially bounce a long way from the batter before going on to bounce again (sometimes more than once) before being within striking distance (Harwood, Yeadon, \& King, 2018a). Batters often play forward to these short balls, contrary to the conventional method which would be to play on the back foot to short deliveries. This means that from a young age batters are learning inappropriate or confused decision-making which they will have to correct as they mature. Not only is this inefficient, but it has the potential to be dangerous as players progress to bat 
against older, faster bowlers who can make a short ball bounce higher and where playing forward could lead to balls striking the batter on the upper body or head.

Looking at the influence of scaling sports equipment and playing areas on motor skill acquisition in children's sport Buszard, Reid, Masters, \& Farrow (2016) highlighted the need to "simplify skill performance whilst maintaining perceptionaction couplings akin to the adult game" (p. 829). Harwood et al. (2018a) found that reducing the length of the pitch halved the number of balls bouncing twice or more in under-11 club cricket, therefore it is likely that batting on a shorter pitch would improve the coupling between judging the length of delivery and selecting the appropriate shot type. In particular it was expected that batters would be more likely to play back foot shots to short deliveries, in line with recommended technique (e.g. Woolmer et al., 2008). The apparent dominance of front foot shots to all deliveries meant it less likely that there would be an increase in the proportion of front foot shots to full deliveries.

Investigating the coupling of delivery length and shot type depended upon having an estimate of where the good length region lies for cricketers in this age group and therefore how far from the stumps a ball must bounce to be considered "short" or "full". In this study the focus was on batting against seam/pace bowling because at the earliest ages of junior competitive cricket very few players spin the ball appreciably (although a small number at county level have begun to develop this bowling style). To determine what constituted a short or full delivery the front or back foot shot selection of top order under-10 county batters was used as an indicator of their judgement of length (Müller et al., 2009; Müller \& Abernethy, 2006; Stevenson, Smeeton, Filby, \& Maxwell, 2015) when facing under-10 county seam bowlers. It was anticipated that there would be a range of ball bounce distances where these skilled batters did not overwhelmingly favour playing forward or backward, indicating the uncertainty which a good length ball induces.

The purpose of this study was therefore first to establish an "uncertainty" or good length region based upon which deliveries could be classified as "short", "good" or "full" in under-10 and 11 cricket. It could then be determined whether club and county batters played a higher proportion of back foot shots to short deliveries and front foot shots to full deliveries in matches played on a shorter pitch when compared to matches played on the currently recommended junior pitch lengths.

\section{METHODS}

Matches and Participants

During an English junior cricket season six county under-10 boys and fourteen under-11 mixed club cricket matches were played on two different pitch lengths (Table 1).

Table 1. Match and player details

\begin{tabular}{lccccc}
\hline & $\begin{array}{c}\text { Pitch length } \\
\text { (yards) }\end{array}$ & $\begin{array}{c}\text { Number of } \\
\text { matches }\end{array}$ & $\begin{array}{c}\text { Number of } \\
\text { teams }\end{array}$ & $\begin{array}{c}\text { Number of } \\
\text { players }\end{array}$ & $\begin{array}{c}\text { Player ages } \\
\text { (years; mean } \pm \mathrm{s} \text { ) }\end{array}$ \\
\hline Club & 20 & 7 & 11 & 92 & $10.41 \pm 0.98$ \\
Club & 16 & 7 & 10 & 98 & $10.46 \pm 0.95$ \\
County & 19 & 3 & 5 & 61 & $10.08 \pm 0.53$ \\
County & 16 & 3 & 4 & 57 & $10.15 \pm 0.50$ \\
\hline
\end{tabular}

Note: Seven club and two county teams played in more than one match (against different opponents) but rotated some players. Age groups based on age at midnight on preceding $31^{\text {st }}$ August; player ages given at the start of the season. Girls were permitted to play in the club matches; only 12 girls played. 
A Level Four county coach selected 16 yards $(14.63 \mathrm{~m})$ for the study, while 19 yards $(17.37 \mathrm{~m})$ and 20 yards $(18.28 \mathrm{~m})$ were the England and Wales Cricket Board (ECB) recommendations in place for under-10s and under-11s respectively. Ethical approval for the study was given by the university ethics committee. Informed consent was obtained from the players' parents and assent given by the players and their clubs/counties.

Club matches were played using an 8-a-side pairs format in which each pair of batters batted for four, six ball overs and each fielder (except the wicket-keeper) bowled two or three overs in a 16 over innings. The county matches were 11-a-side limited overs format following the Laws of Cricket in effect at the time (Marylebone Cricket Club, 2015).

\section{Data collection and coding}

A Panasonic DMC-FZ200 camera recorded HD MP4 video at $30 \mathrm{fps}$ and shutter speed of $1 / 125^{\text {th }} \mathrm{s}$ throughout each innings from just outside of the boundary, midway along and perpendicular to the pitch. The lens was zoomed-in so that the field of view included the length of the pitch from wicket to wicket plus approximately one meter at either end.

From the videos, two experienced cricketers, one a level two coach and the other a cricket performance analyst, independently categorized each shot played as either front foot or back foot. Deliveries to which the batters played a shot but missed the ball were included, while deliveries which batters did not attempt to play were noted as such but omitted. Very occasionally there was no clear foot movement or shot type so those deliveries were also noted but excluded.

A comparison between the two codings of 4548 deliveries revealed only 219 discrepancies, 95.2\% agreement. Where disagreements occurred the lead investigator reviewed the video and decided whether there was a clear choice of shot or whether the delivery should be excluded (13 deliveries excluded in total). In county matches the distinct front or back foot shots totalled 707 on the 16 yard and 1054 on the 19 yard pitches, and in club matches 1191 on 16 yard and 1188 on 20 yard pitches.

For each delivery the lead investigator also digitized the distance at which the ball bounced from the batter's stumps in conjunction with the shot type (front or back foot), all distances being scaled using the relevant pitch length. To determine the good length region for cricketers of this age, the shot selection by the top order batters (up to the first five batters where five or more were required to bat) against seam bowling in each of the county matches was analysed. This amounted to 29 batters playing 431 shots in the 16 yard matches and 29 batters playing 518 shots in the 19 yard matches.

\section{Data analysis}

A Probit analysis (Finney, 1971) was conducted in SPSS to identify the distance from their stumps at which the top order county batters were equally likely to play front foot or back foot shots, in a similar way to Stevenson, Smeeton, Filby, \& Maxwell (2015). This generated a response probability model, with ball pitching distance as the independent variable and probability of back foot shot selection as the dependent variable.

Between 5 and 7 yards ( 4.6 to $6.4 \mathrm{~m}$ ) from the stumps, the area anticipated to contain the transition from "more likely front foot" to "more likely back foot", 
responses were grouped into bins of a quarter of a yard $(0.23 \mathrm{~m}$; just over three ball diameters) and outside of this range half-yard bins were used. In each bin the probability of a back foot shot as a proportion of the total deliveries landing in that area was calculated. Very short and very full deliveries (more than 8.5 yards and less than 4 yards respectively) were excluded as very small numbers (two or fewer in this case) of front or back foot observations at a particular length render the modelling of the data unreliable. A total of 294 deliveries fell at the two extremes.

Transition distance estimates with 95\% confidence intervals were made for each pitch length separately and also with the data from the two pitch lengths combined. Based on the mean size of the good length regions for adults highlighted in Figure $1(1.80 \mathrm{~m} / 1.97$ yards) and scaled in proportion to stature, good length regions 1.5 yards in length were determined with the transition distance estimates at their centre. Balls pitching further from the batters' stumps than the upper end of this range were deemed "short" and those closer to the stumps than the lower end were deemed "full".

Using these age-specific estimates for short, good and full length deliveries, the proportions (expressed per 100 deliveries) of each length in the county and club matches were compared between pitch lengths. Frequencies of front and back foot shots played by all batters to full and short balls respectively on each pitch length at both levels of competition were also calculated. Inter-pitch length differences between the proportions of back foot shots to short deliveries were calculated for county and club matches separately, as were the differences between proportions of front foot shots to full deliveries. Ninety-five percent confidence intervals around the differences between proportions were estimated according to the recommended method of Newcombe \& Altman (2000) as implemented in ESCI (Exploratory Software for Confidence Intervals; Cumming, 2016). The differences between the proportions were the effect size estimates of interest and the magnitudes of these were related directly to the cricket environment: a difference equivalent to at least once per over (i.e. $\geq 1$ in 6 , or 16.7 per 100 deliveries) was defined as a large effect; at least once in two overs ( $\geq 8.3$ per 100 deliveries) as moderate; at least once in four overs ( $\geq 4.2$ per 100 deliveries) as small; and anything less as trivial.

\section{RESULTS}

The Pearson Goodness of Fit tests showed that the Probit models represented the 16 yard $(P=0.2), 19$ yard $(P=0.68)$ and combined $(P=0.48)$ foot movement data of the top order county batters well. The Probit estimates of the transition distance from predominantly front foot to predominantly back foot shots for the 16 yard and 19 yard data were 5.91 yards, $95 \% \mathrm{Cl}[5.69,6.14]$ and 5.64 yards [5.43, 5.84 ] respectively. Cumming (2009) demonstrated that a $50 \%$ overlap of confidence intervals equates to conservative estimate of $P=0.05$ for the difference between independent proportions; the $70 \%$ overlap of the confidence intervals here confirmed that these estimates were not significantly different (Figure 2). Furthermore the difference of just 0.27 yards $(0.25 \mathrm{~m})$ is less than four ball diameters, so a small difference in practical terms. Therefore the transition distance of 5.76 yards $(5.27 \mathrm{~m})$ calculated using the combined data was taken to be the middle of the good length or uncertainty region. A "full" delivery was then defined as one pitching less than 5.0 yards $(4.57 \mathrm{~m})$ from the batters' stumps and a "short" delivery as one pitching more than 6.5 yards $(5.94 \mathrm{~m})$ from them. Inspection of the Probit model output showed that 5 yards coincided with the length at which batters would be expected to play forward 
$70 \%$ of the time (i.e. back 30\%) and 6.5 yards coincided with expecting batters to play back $70 \%$ of the time (Figure 3 ).

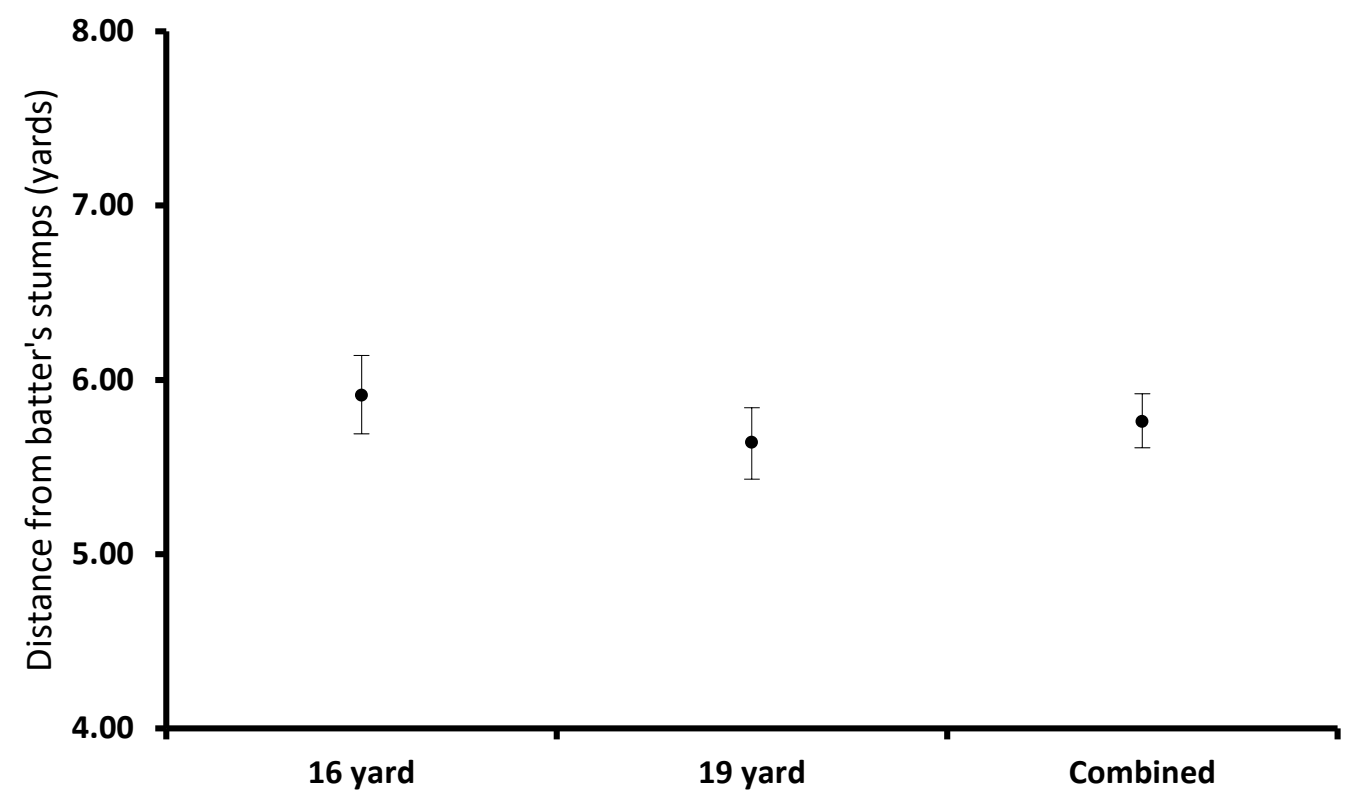

Figure 2. Probit estimates of the transition distances based on data from 16 yard and 19 yard pitches, and the estimate from the combined data. Error bars are $95 \%$ confidence intervals.

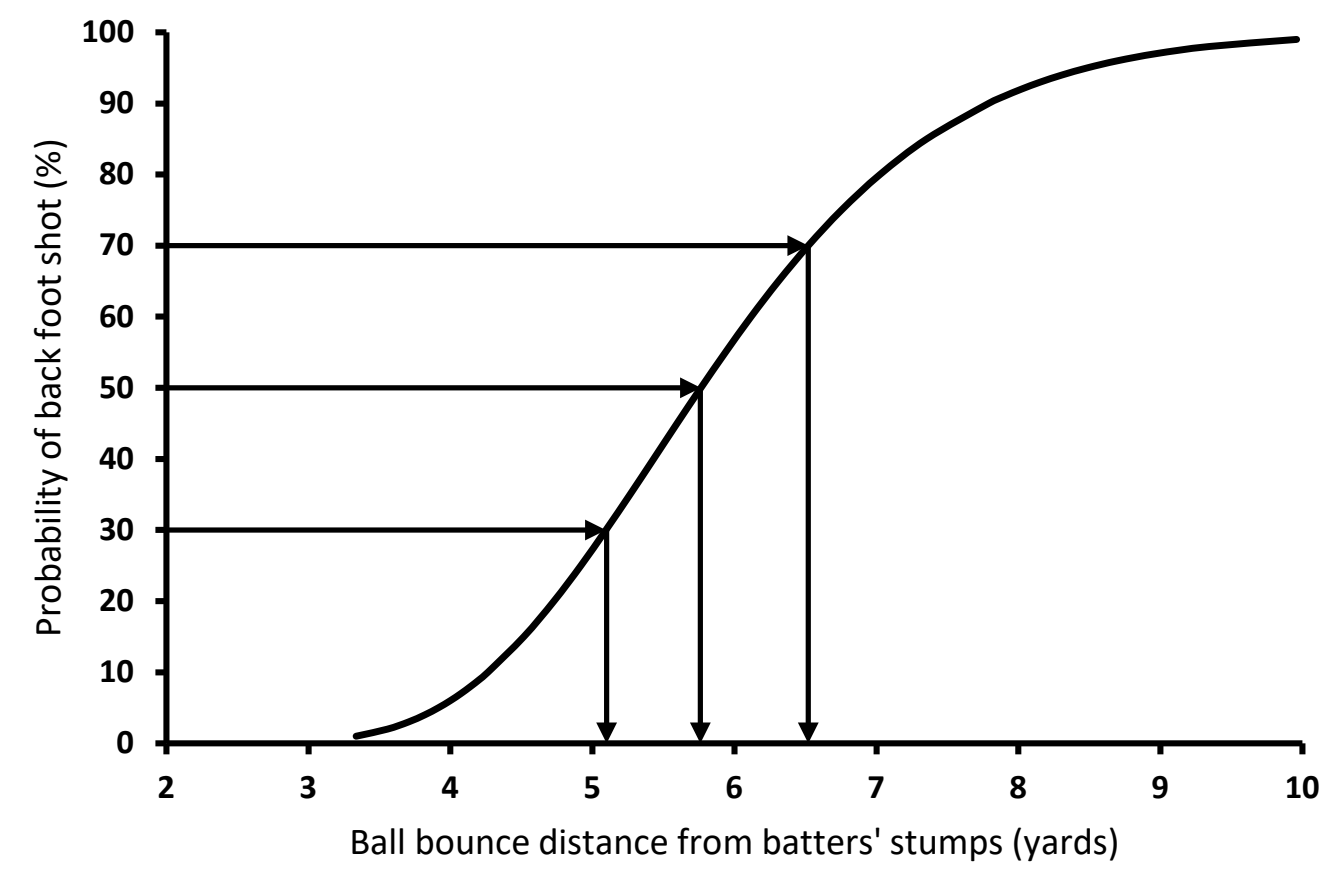

Figure 3. Probit model curve of back foot shot probability in relation to ball bounce distance from the batter's stumps. Distances corresponding to $30 \%, 50 \%$ and $70 \%$ probabilities highlighted.

The proportion of short deliveries on the 16 yard pitches was clearly lower than on the longer pitches (Table 2), a moderate difference of 8 per hundred deliveries, $95 \% \mathrm{Cl}[4.2,12.2]$, in county matches and a large difference of 21 per 100 deliveries $[17.8,24.8]$, in club matches. On the 16 yard pitches the proportion of short deliveries was similar in both club and county matches, while in club matches there were nearly 20 more full deliveries per hundred [15.5, 23.4]. Other differences were less than 4.2 per hundred deliveries and as such of no practical importance (Figure 4). 
Table 2. The proportions of full toss, full, good and short length deliveries (per 100 deliveries) for each match type and pitch length, and the differences between these proportions

\begin{tabular}{ccrrc}
\hline & Full toss & Full & Good & \multicolumn{1}{c}{ Short } \\
\hline County 19 & 5.5 & 43.6 & 22.6 & 28.4 \\
County 16 & 6.8 & 47.7 & 25.5 & $-8.3^{*}$ \\
Difference & 1.3 & 4.1 & 2.9 & \\
& & & & \\
& & & & 38.6 \\
Club 20 & 3.5 & 36.7 & 21.1 & 17.3 \\
Club 16 & 7.6 & 56.2 & 19.0 & $-21.3^{* *}$ \\
Difference & 4.0 & $19.5^{* *}$ & -2.2 & \\
\hline
\end{tabular}

Note: ${ }^{* *}=$ large effect size; ${ }^{*}=$ moderate effect size. Positive difference indicates a higher proportion in the short pitch matches.

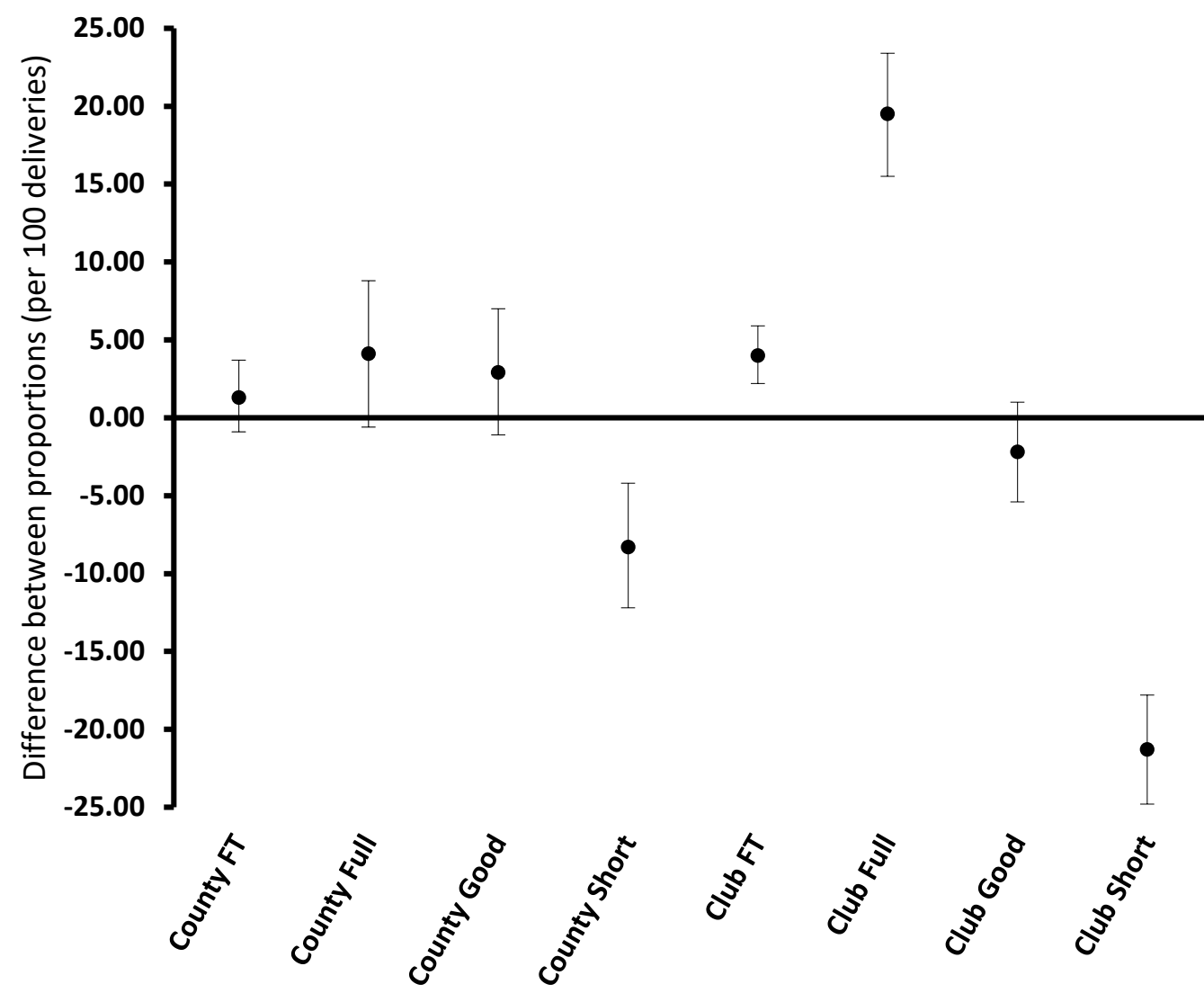

Figure 4. Differences between proportions of full toss (FT), full, good length and short deliveries for county and club matches. Error bars are $95 \%$ confidence intervals.

Although the proportion of short balls was lower on 16 yard pitches, both county and club matches saw a greater proportion of back foot shots to short deliveries (Figure 5). In the county matches it was $7 \%$ higher, 75 per hundred deliveries compared with 70 , a moderate effect of $5,[-4.1,13.5]$, although the $95 \%$ confidence interval includes the possibility of no difference. In the club matches the back foot shots to short balls proportion on short pitches was more than double that on the longer pitches, 19 compared with 9 , a large effect of 10 , [4.6, 16.5]. The proportion of front foot shots to full balls was greater in 16 yard pitch county matches, a moderate difference of $6,[2.3,8.7], 97$ compared with 92 (6\% higher). In club matches the difference was negligible. 


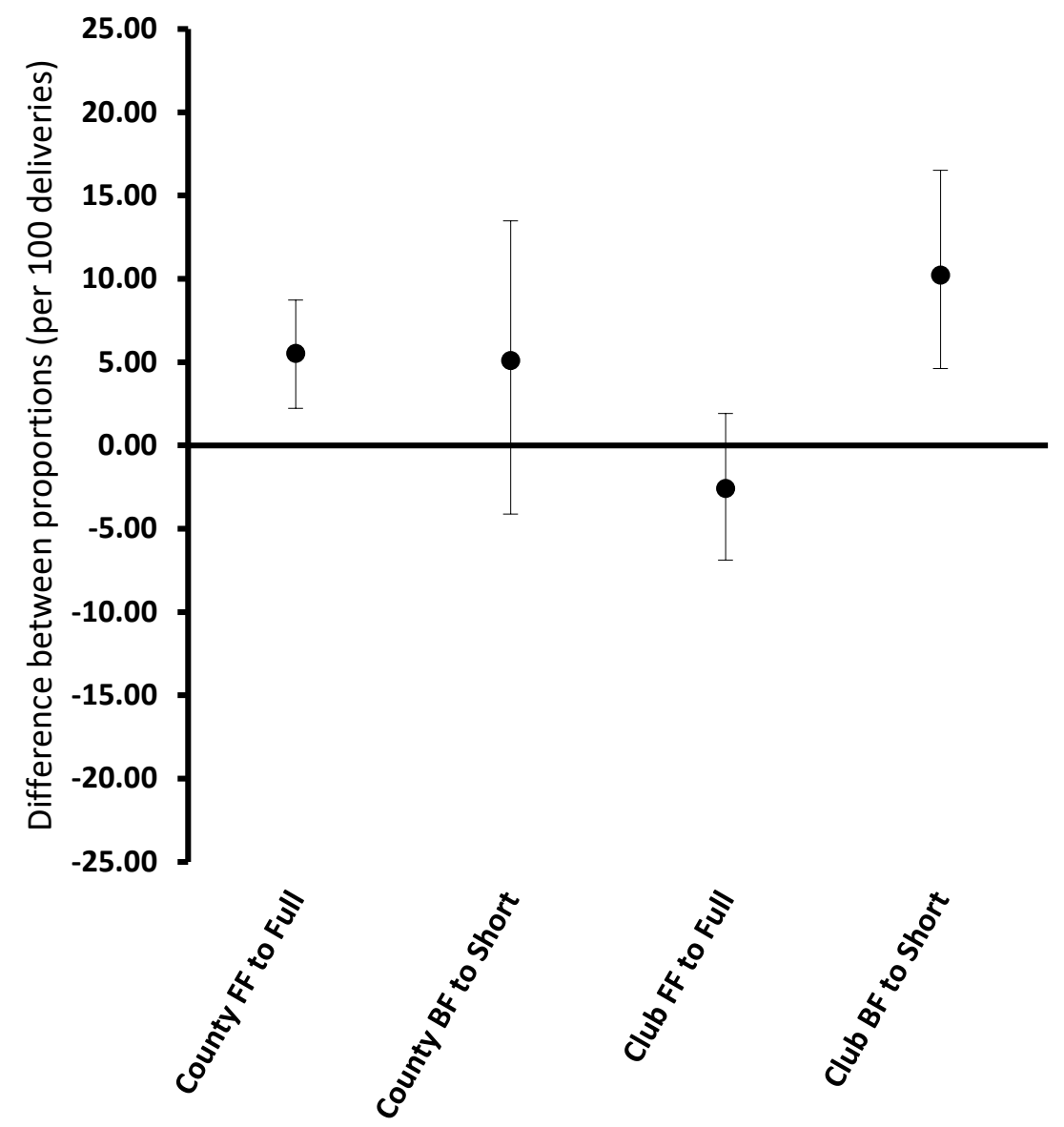

Figure 5. Differences between proportions of front foot (FF) shots to full deliveries and back foot (BF) shots to short deliveries for county and club matches. Error bars are $95 \%$ confidence intervals.

\section{DISCUSSION}

Successful batting depends critically on establishing an appropriate link between the batter's perception of where the cricket ball will bounce (the delivery length) and gross foot movement, forward or backward. In order to make meaningful inferences about shot decisions the concepts of short, good and full length deliveries were defined for the age of the players. The Probit analysis enabled a 1.5 yard (1.4 $\mathrm{m})$ "good length region" from 5.0 to 6.5 yards $(4.6$ to $5.9 \mathrm{~m})$ from the batters' stumps to be calculated. Within this region the batters were estimated to be at best $70 \%$ sure whether to play front or back foot shots, emphasising the uncertainty that this length of delivery induces. This area is effectively a meta-stable region as described by Pinder, Davids, \& Renshaw (2012), though for their "junior" batters (aged $16.3 \pm 0.3$ years and almost of average adult stature), their region was 6.5 to $7.5 \mathrm{~m}$ from the batters' stumps. They specified their region a priori but subsequently found a $48 \%$ forward, $52 \%$ backward choice of movement responses when balls pitched between these lengths. Scaled just in proportion to average height, the centre of their metastable region would lie at $5.5 \mathrm{~m}$ (6.0 yards) for a ten year old, in reasonable agreement with the 5.76 yards determined here.

On currently recommended pitch lengths young players often play forward to balls to which, based solely on the ball bounce location, they should play back. This study found that playing on a shorter pitch increased the likelihood that under-10 and under-11 county and club cricketers would play back to short deliveries. The higher 
proportion of back foot shots played to short balls on short pitches is an important difference, particularly in club matches where it was more than double that on the longer pitches. Recognising short pitched deliveries and moving onto the back foot is characteristic of skilled batters (Woolmer et al., 2008) and shorter pitches encouraged this in the young club players. However it is interesting to consider why, at only 19 back foot shots per 100 short deliveries compared with 75 per hundred in county matches, the proportion wasn't higher.

Firstly, playing forward to a short ball is not necessarily the wrong choice if, as is quite common in the younger club age groups, the bowling is slow and the bounce of the pitch is low. Secondly, there may be a considerable response bias towards playing front foot shots. Pinder et al. (2012) noted that batting against full deliveries is "practiced almost exclusively in the developmental stages of cricket batting" (p. 439), so young club players become more comfortable with the front foot drive. This is reasonably effective even against short deliveries if the ball isn't bouncing very high or on the traditionally longer pitches where the ball may bounce twice or more before reaching the batter. On a shorter pitch, front foot shots to short balls are less effective, making players more likely to learn back foot skills implicitly and to be coached to play them explicitly. County players already have more experience of playing against quicker bowling on better prepared pitches and have also received coaching which is more likely to have included playing back foot shots hence the higher proportions of back foot shots in county matches on both pitch lengths. A third reason may be that batters expect a full delivery if they are unsure of the length. Visual occlusion studies of batting have found that even skilled adult batters favour a front foot shot if they are uncertain about the length of the delivery (Abernethy \& Russell, 1984; McLeod, 1987; Müller \& Abernethy, 2006; Müller et al., 2006). Playing on appropriately scaled pitches throughout their development should mean that young players in future exhibit less bias towards front foot shots.

Müller \& Abernethy (2012) set out the three, sequential sources of information aiding a batter's decision making in striking sports: expectations and situational probabilities; pre-release information based on the bowler's kinematics; and observation of the early flight. It is unlikely that expectation and situational probability are used by young batters even on shorter pitches, not least because the bowlers themselves are unlikely to have the skill or tactical knowledge to bowl to a particular plan. Similarly, considering young tennis players Farrow \& Reid (2012) suggested that "situational probability information may not exist or at best is extremely inconsistent and hence unable to be relied upon to drive anticipatory performance." (p. 372).

Several studies of cricket and other interception sports have found that experts are able to utilize cues from opponents' pre-delivery or shot preparation kinematics in order to select and organize appropriate shot responses (e.g. Abernethy, 1990; Abernethy \& Russell, 1984, 1987; Brenton, Müller, \& Mansingh, 2016; Müller et al., 2009, 2006; Penrose \& Roach, 1995; Shim, Carlton, Chow, \& Chae, 2005). However Farrow \& Reid (2012), Müller \& Abernethy (2012) and Weissensteiner, Abernethy, Farrow, \& Müller (2008) noted that the temporal demands at junior and lower skilled levels are unlikely to require players to use anticipation in order to succeed. Indeed ten and eleven year old batters rarely appear hurried on 19 or 20 yard pitches: the ball isn't moving quickly and has quite a long way to travel. Müller et al. (2006) found that skilled batters used pre-release information in their judgment of length against medium pace but not spin bowling and suggested that some flight information is critical when batting against spin. However it could be a case of the batters not risking an incorrect judgement when they have time to be more certain; in other 
words not committing to the shot too soon. This would agree with the speculation that tennis players are likely to use anticipation mainly when waiting longer would leave them insufficient time to respond successfully to their opponent's shot (Triolet, Benguigui, Le Runigo, \& Williams, 2013). Although it has been suggested that nonexperts cannot use early information from opponent's movement pattern to anticipate (Müller \& Abernethy, 2012), in the case of junior batters on long pitches it is likely that they rarely need to.

A shorter pitch will add to the time pressure on the batter even though the bowling isn't faster (Elliott, Plunkett, \& Alderson, 2005; Harwood, Yeadon, \& King, $2018 \mathrm{~b}$ ): the ball arrives in the hitting area sooner, even though it is in the area for the same amount of time. This reduced time to choose the appropriate shot imposes a task constraint on the batters which will increase their need to attend more to the predelivery movements of the bowlers and should encourage the development of the anticipation skills that batters need to progress towards expertise (Penrose \& Roach, 1995; Weissensteiner et al., 2008). Studies have also suggested that coincidenceanticipation skills are quite well developed by around the age of 11 (e.g. Benguigui \& Ripoll, 1998; Dorfman, 1977; Kim, Nauhaus, Glazek, Young, \& Lin, 2013) which suggests that players of this age are ready to be challenged to develop these skills in the competitive environment and to establish the perception-action couplings required at older, more advanced levels of the game.

The 16 yard pitch length selected by a highly experienced coach is shorter than the $16 \mathrm{~m}$ (17.5 yard) pitch length recently proposed for under-11 cricket in Australia (Cricket Australia, 2017). Differences between playing conditions (e.g. artificial turf pitches are frequently used in Australia) are likely to be a factor in this difference, but further work is required to determine the optimal length of pitch for the age group.

The high ecological validity of the data in this study was at the expense of control of the participants and conditions, such that the number of deliveries faced by each batter in total and from a given bowler, as well as the pitch surface itself, could not be regulated. The high volume of data both in terms of deliveries faced and the number and quality of participants compensated for the lack of control. It would be possible to conduct a study of footwork in a more controlled setting as Stevenson et al. (2015) did, however shot selection in a net or other artificial setting without a consequence for a false shot is never as realistic.

\section{CONCLUSIONS}

In club matches on 16 yard pitches the proportion of back foot shots to short deliveries was double that on the traditional, 20 yard pitches, even though the proportion of short balls was lower. This is an important change and the perceptionaction coupling between delivery length and shot selection for club players should become more like that currently exhibited at older ages and higher standards as a result. The difference in county matches was less pronounced but in the same direction. For both levels of play, the increased task demand of the shorter pitch should lead to improved anticipation skills, with batters attending more to bowlers' kinematics and their outcomes. As more leagues adopt shorter pitches coaches should place more emphasis on back foot shot techniques and increase the exposure of young batters to shorter, higher bouncing deliveries in practice. The empirically derived good length region determined in this study, where batters are least certain whether to play forward or back, provides valuable information to coaches and young bowlers in particular. 


\section{DISCLOSURE STATEMENT}

No conflict of interest was reported by the authors.

\section{REFERENCES}

Abernethy, B. 1990. Anticipation in squash: Differences in advance cue utilization between expert and novice players. Journal of Sports Sciences, 8, 17-34.

Abernethy, B., Russell, D.G. 1984. Advance cue utilisation by skilled cricket batsmen. Australian Journal of Science and Medicine in Sport, 16, 2-10.

Abernethy, B., Russell, D.G. 1987. Expert-novice differences in an applied selective attention task. Journal of Sport Psychology, 9, 326-345.

Ball, K., Hrysomallis, C. 2012. Synthetic grass cricket pitches and ball bounce characteristics. Journal of Science and Medicine in Sport, 15, 272-276.

Benguigui, N., Ripoll, H. 1998. Effects of tennis practice on the coincidence timing accuracy of adults and children. Research Quarterly for Exercise and Sport, 69, 217-223.

Bradman, D. 1958. The Art of Cricket. London: Hodder \& Stoughton.

Brenton, J., Müller, S., Mansingh, A. 2016. Discrimination of visual anticipation in skilled cricket batsmen. Journal of Applied Sport Psychology, 28, 483-488.

Buszard, T., Reid, M., Masters, R., Farrow, D. 2016. Scaling the equipment and play area in children's sport to improve motor skill acquisition: A systematic review. Sports Medicine, 46, 829-843.

Cricket Australia. 2017. Junior playing formats. Retrieved August 1, 2017, from http://community.cricket.com.au/clubs/junior-formats/format-summary

Cumming, G. 2009. Inference by eye: Reading the overlap of independent confidence intervals. Statistics in Medicine, 28, 205-220.

Cumming, G. 2016. Exploratory Software for Confidence Intervals (ESCl). Retrieved from http://routledgetextbooks.com/textbooks/9781138825529/student.php

Dorfman, P.W. 1977. Timing and anticipation: A developmental perspective. Journal of Motor Behavior, 9, 67-79.

Elliott, B.C., Plunkett, D., Alderson, J. 2005. The effect of altered pitch length on performance and technique in junior fast bowlers. Journal of Sports Sciences, 23, 661-667.

Farrow, D., Reid, M. 2012. The contribution of situational probability information to anticipatory skill. Journal of Science and Medicine in Sport, 15, 368-373.

Finney, D.J. 1971. Probit analysis (3rd ed.). London, England: Cambridge University Press.

Glazier, P.S., Paradisis, G.P., Cooper, S.M. 2000. Anthropometric and kinematic influences on release speed in men's fast-medium bowling. Journal of Sports Sciences, 18, 1013-1021.

Harwood, M.J., Yeadon, M.R., King, M.A. 2018a. Reducing the pitch length: Effects on junior cricket. International Journal of Sports Science and Coaching, 13, 10311039.

Harwood, M.J., Yeadon, M.R., King, M.A. 2018b. Does shortening the pitch make junior cricketers bowl better? Journal of Sports Sciences, 36, 1972-1978.

James, D.M., Carré, M.J., Haake, S.J. 2004. The playing performance of county cricket pitches. Sports Engineering, 7, 1-14. 
Justham, L., Cork, A., West, A.A. 2010. Comparative study of the performances during match play of an elite-level spin bowler and an elite-level pace bowler in cricket. Proceedings of the Institution of Mechanical Engineers, Part P: Journal of Sports Engineering and Technology, 224, 237-247.

Justham, L., West, A.A., Harland, A., Cork, A. 2006. Quantification of the cricket bowling delivery: A study of elite players to gauge variability and controllability. The Engineering of Sport 6, 1, 205-210.

Kim, R., Nauhaus, G., Glazek, K., Young, D., Lin, S. 2013. Development of coincidence-anticipation timing in a catching task. Perceptual \& Motor Skills, 117, 319-338.

Marylebone Cricket Club. 2015. The Laws of Cricket (2000 Code 6th Edition - 2015). London: Marylebone Cricket Club.

McLeod, P. 1987. Visual reaction time and high-speed ball games. Perception, 16, 49-59.

Müller, S., Abernethy, B. 2006. Batting with occluded vision: An in situ examination of the information pick-up and interceptive skills of high- and low-skilled cricket batsmen. Journal of Science and Medicine in Sport, 9, 446-458.

Müller, S., Abernethy, B. 2012. Expert anticipatory skill in striking sports: A review and a model. Research Quarterly for Exercise and Sport, 83, 175-187.

Müller, S., Abernethy, B., Farrow, D. 2006. How do world-class cricket batsmen anticipate a bowler's intention? Quarterly Journal of Experimental Psychology, 59, 2162-2186.

Müller, S., Abernethy, B., Reece, J., Rose, M., Eid, M., McBean, R., ... Abreu, C. 2009. An in-situ examination of the timing of information pick-up for interception by cricket batsmen of different skill levels. Psychology of Sport and Exercise, 10, 644-652.

Newcombe, R., Altman, D.G. 2000. Proportions and their differences. In D.G. Altman, D. Machin, T.N. Bryant, \& M.J. Gardner (Eds.), Statistics with confidence: Confidence intervals and statistical guidelines (Second edi, pp. 45-56). London, England: BMJ Books.

Penrose, J.M.T., Roach, N.K. 1995. Decision making and advanced cue utilisation by cricket batsmen. Journal of Human Movement Studies, 29, 199-218.

Petersen, C.J., Wilson, B.D., Hopkins, W.G. 2004. Effects of modified-implement training on fast bowling in cricket. Journal of Sports Sciences, 22, 1035-1039.

Pinder, R.A., Davids, K., Renshaw, I. 2012. Metastability and emergent performance of dynamic interceptive actions. Journal of Science and Medicine in Sport, 15, 437-443.

Roca, M., Elliott, B., Alderson, J., Foster, D. 2006. The relationship between shoulder alignment and elbow joint angle in cricket fast-medium bowlers. Journal of Sports Sciences, 24, 1127-1135.

Sarpeshkar, V., Mann, D.L., Spratford, W., Abernethy, B. 2017. The influence of ballswing on the timing and coordination of a natural interceptive task. Human Movement Science, 54, 82-100.

Shim, J., Carlton, L.G., Chow, J.W., Chae, W.-S. 2005. The use of anticipatory visual cues by highly skilled tennis players. Journal of Motor Behavior, 37, 164-175.

Stevenson, K.P., Smeeton, N.J., Filby, W.C.D., Maxwell, N.S. 2015. Assessing representative task design in cricket batting: Comparing an in-situ and laboratorybased task. International Journal of Sport Psychology, 46, 758-779. 
Triolet, C., Benguigui, N., Le Runigo, C., Williams, M. 2013. Quantifying the nature of anticipation in professional tennis. Journal of Sports Sciences, 31, 820-830.

Weissensteiner, J., Abernethy, B., Farrow, D., Müller, S. 2008. The development of anticipation: A cross-sectional examination of the practice experiences contributing to skill in cricket batting. Journal of Sport \& Exercise Psychology, 30, 663-684.

Wickington, K., Linthorne, N. 2017. Effect of Ball Weight on Speed, Accuracy, and Mechanics in Cricket Fast Bowling. Sports, 5.

Woolmer, R.A., Noakes, T., Moffett, H. 2008. Bob Woolmer's art and science of cricket. London: New Holland. 